\title{
Simple heat transfer correlations for turbulent tube flow
}

\author{
Dawid Taler ${ }^{1, *}$ and Jan Taler $^{2}$ \\ ${ }^{1}$ Institute of Heat Engineering and Air Protection, Cracow University of Technology, 31-155 Cracow, Poland \\ ${ }^{2}$ Institute of Thermal Power Engineering, Cracow University of Technology, 31-864 Cracow, Poland
}

\begin{abstract}
The paper presents three power-type correlations of a simple form, which are valid for Reynolds numbers range from $3 \cdot 10^{3} \leq \operatorname{Re} \leq 10^{6}$, and for three different ranges of Prandtl number: $0.1 \leq \operatorname{Pr} \leq 1.0$, $1.0<\operatorname{Pr} \leq 3.0$, and $3.0<\operatorname{Pr} \leq 10^{3}$. Heat transfer correlations developed in the paper were compared with experimental results available in the literature. The comparisons performed in the paper confirm the good accuracy of the proposed correlations. They are also much simpler compared with the relationship of Gnielinski, which is also widely used in the heat transfer calculations.
\end{abstract}

\section{Introduction}

Heat transfer correlations for turbulent fluid flow in the tubes are commonly used in the design and performance calculations of heat exchangers [1-4]. The value of heat transfer coefficient significantly affects the value of the thermal stress [5]. Time changes in optimum fluid temperature determined from the condition of not exceeding the stress at a point lying on the inner surface of the pressure component, very strong depend on the heat transfer coefficient [6-9]. Therefore, continuous experimental research is carried out to find a straightforward and accurate heat transfer correlations. The empirical correlation of Dittus-Boelter [10-12] has gained widespread acceptance for prediction of the Nusselt number with turbulent flow in the smoothsurface tubes

$$
\mathrm{Nu}=0.023 \operatorname{Re}^{0.8} \operatorname{Pr}^{n}
$$

$$
0.6 \leq \operatorname{Pr} \leq 160, \quad \operatorname{Re} \geq 10^{4}, \quad L / d_{w} \geq 60
$$

where : $\mathrm{Nu}=h d_{w} / k, \operatorname{Re}=u_{m} d_{w} / v, \operatorname{Pr}=c_{p} \mu / k$, $d_{w}=2 r_{w}$ - inner diameter of the tube, $L-$ tube length, $h$ - heat transfer coefficient, $k$ - thermal conductivity, $u_{m}$ - mean velocity of the fluid, $c_{p}$ - specific heat at constant pressure, $v=\mu / \rho$ - kinematic viscosity, $\mu$-dynamic viscosity, $\rho$ - fluid density.

The exponent of the Prandtl number is $n=0.4$ for heating of the fluid and $n=0.3$ if the fluid is being cooled. The similar power-type relationship of Colburn is based on the Chilton-Colburn analogy for heat and momentum transfer [13]

$$
\mathrm{Nu}=0.023 \operatorname{Re}^{0.8} \operatorname{Pr}^{1 / 3}
$$

$$
0.6 \leq \operatorname{Pr} \leq 160, \quad \operatorname{Re} \geq 10^{4}, \quad L / d_{w} \geq 60
$$

The correlations (1) and (2) are valid for moderate temperature differences $\left|T_{w}-T_{m}\right|$ under which properties may be evaluated at the mean bulk temperature $\bar{T}_{m}$. When variations of physical properties are significant, the Sieder and Tate relationship [14] can be used

$$
\begin{gathered}
\mathrm{Nu}=0.027 \operatorname{Re}^{0.8} \operatorname{Pr}^{1 / 3}\left(\frac{\mu_{m}}{\mu_{w}}\right)^{0.14} \\
0.7 \leq \operatorname{Pr} \leq 16,700, \quad \operatorname{Re} \geq 10^{4}, \quad L / d_{w} \geq 60
\end{gathered}
$$

where all properties are evaluated at the local bulk temperature $T_{m}$ except the viscosity $\mu_{w}$ that is estimated at the wall surface temperature $T_{w}$.

However, the power-type correlations like DittusBoelter, Colburn, and Colburn relationships do not provide good approximations within larger ranges of the experimental data because of its simple form. The power type correlation like that of Dittus-Boelter is not able to approximate the experimental results over a broad range of the Prandtl number. The maximum deviation between experimental data and predictions using Eq. (1) is about $20 \%$ [15-17]. When the working medium is water, the Dittus-Boelter relationship (1) overpredicts the heat transfer coefficient for smaller Reynolds numbers when $\operatorname{Re}<10,000$ and underpredicts for higher Reynolds numbers [18]. In the last forty years, the power-type equations (1-3) were often being replaced by the

\footnotetext{
* Corresponding author: dtaler@pk.edu.pl
} 
Gnielinski correlation [19-20]

$$
\begin{aligned}
& \mathrm{Nu}=\frac{\frac{\xi}{8}(\operatorname{Re}-1000) \operatorname{Pr}}{1+12.7 \sqrt{\frac{\xi}{8}}\left(\operatorname{Pr}^{2 / 3}-1\right)}\left[1+\left(\frac{d_{w}}{L}\right)^{2 / 3}\right]\left(\frac{\operatorname{Pr}_{m}}{\operatorname{Pr}_{w}}\right)^{0.11} \\
& 4 \cdot 10^{3} \leq \operatorname{Re} \leq 10^{6}, \quad 0.5 \leq \operatorname{Pr} \leq 200
\end{aligned}
$$

where the symbol $\xi$ denotes the friction factor for smooth tubes calculated from the Filonienko relationship [21]

$$
\xi=(1.82 \log \operatorname{Re}-1.64)^{-2}
$$

The symbols $\operatorname{Pr}_{\mathrm{m}}$ and $\operatorname{Pr}_{\mathrm{w}}$ designates the Prandtl number at the bulk and wall temperature, respectively.

The Gnielinski relationship (4) is a modification of the Petukhov formula [22]

$$
\begin{gathered}
\mathrm{Nu}=\frac{\frac{\xi}{8} \operatorname{Re} \operatorname{Pr}}{1.07+12.7 \sqrt{\frac{\xi}{8}}\left(\operatorname{Pr}^{2 / 3}-1\right)}\left(\frac{\mu_{m}}{\mu_{w}}\right)^{n} \\
10^{4} \leq \operatorname{Re} \leq 10^{6}, \quad 0.5 \leq \operatorname{Pr} \leq 200
\end{gathered}
$$

to increase the accuracy of Eq. (6) for smaller Reynolds numbers. In Eqs. (4) and (6), the subscript $m$ refers to evaluating the fluid properties at the mean (bulk) average temperature $\bar{T}_{m}$ that is usually defined as the average of the inlet and exit bulk temperature. The subscript $w$ refers to the evaluation of the fluid properties at the wall surface temperature $T_{w}$. The exponent $n$ in Eq. (6) is equal to 0.11 for $T_{w}>\bar{T}_{m}$ and $n=0.25$ for $T_{w}<\bar{T}_{m}$. The constant $n$ is equal zero for gases. The relationship (4) of Gnielinski is very widely used, as well approximates the experimental data [17, 23-25].

In recent years, however, a new rise in popularity of power-type correlation to an approximation of the measurement data is observed [24-26].

The thermal-hydraulic performance of a dimpled enhanced tube was studied experimentally and numerically by Li et al. [24]. The power type correlation based on the experimental results was proposed. The Wilson method was used to adjust unknown constants in the searched relationship. The Prandtl number changed from 5.2 to 30.7 and the Reynolds number from 500 to 8,000 .

Simple power correlations are also proposed to fit experimental data for turbulent flows of nanofluids in tubes. Li and Xuan [25] and Azmi and al. [26] also used electrically heat tubes to study hydrodynamically fully developed flow. Before starting the actual experiments with nanofluids, tests were conducted in which the working fluid was water [25] or a mixture of water and ethylene glycol [26]. The Reynolds number varied in the study of Azmi et al. from 3,000 to 25,000. The Nusselt numbers determined experimentally showed good agreement with the Nusselt numbers obtained from the Dittus-Boelter equation.

$\mathrm{Li}$ and Xuan [25] also found a heat transfer correlation for internal flow of $\mathrm{Cu}$-water nanofluid that for water reduces to

$$
\begin{gathered}
\mathrm{Nu}=0.0059 \mathrm{Re}^{0.9238} \operatorname{Pr}^{0.4} \\
2.5 \cdot 10^{3} \leq \mathrm{Re} \leq 2.5 \cdot 10^{4}
\end{gathered}
$$

Previous studies indicate that power-type correlations are still used successfully to approximate the experimental results when the Reynolds and Prandtl numbers vary in a narrow range.

Unknown constants occurring in the power-type relationships can be readily determined by standard [27] or modified [28] Wilson method while maintaining reasonable effort.

Easy determination of searched constants based on the experimental results is also the reason for the use of power type functions to find heat transfer correlations for the turbulent flow of nanofluids or molten salts in tubes.

\section{Nusselt numbers for turbulent tube flow}

Energy conservation equation for turbulent tube flow averaged by Reynolds has the following form [23, 29]

$$
\rho c_{p} \bar{u} \frac{\partial \bar{T}}{\partial x}=\frac{1}{r} \frac{\partial}{\partial r}(r q)
$$

where: $q$ - heat flux density, $x$ - Cartesian coordinate, $r$ - radius, $\bar{u}$ - time averaged velocity.

The heat flux $q$ consists of the molecular $q_{m}$ and turbulent $q_{t}$ component

$$
q=q_{m}+q_{t}
$$

where

$$
q_{m}=k \frac{\partial \bar{T}}{\partial r}, \quad q_{t}=\rho c_{p} \varepsilon_{q} \frac{\partial \bar{T}}{\partial r}=k \frac{\operatorname{Pr}}{\operatorname{Pr}_{t}} \frac{\varepsilon_{\tau}}{\nu} \frac{\partial \bar{T}}{\partial r}
$$

The symbols in Eq. (10) stand for: $\bar{T}$ - time averaged temperature, $\varepsilon_{q}$ - eddy diffusivity for heat transfer, $\varepsilon_{\tau}$ eddy diffusivity for momentum transfer (turbulent kinematic viscosity), $\operatorname{Pr}_{t}=\varepsilon_{\tau} / \varepsilon_{q}$ - turbulent Prandtl number. Equation (8) is subject to the following boundary conditions

$$
\left.k \frac{\partial \bar{T}}{\partial r}\right|_{r=r_{w}}=q_{w}
$$




$$
\begin{aligned}
& {\left.\left[\frac{\partial \bar{T}}{\partial r}\right]\right|_{r=0}=0} \\
& \left.\bar{T}\right|_{x=0}=\left.T_{m}\right|_{x=0}
\end{aligned}
$$

where $q_{w}$ is the wall heat flux. The mass averaged (bulk) temperature $T_{m}(x)$ is defined as follows

$$
T_{m}(x)=\frac{2}{r_{w}^{2} u_{m}} \int_{0}^{r_{w}} \bar{u}(r) \bar{T}(x, r) r \mathrm{~d} r
$$

The time averaged velocity profile $\bar{u}(r)$ in tube crosssection is necessary to determine the temperature distribution in the fluid. The eddy diffusivity for momentum transfer $\varepsilon_{\tau}$ and time averaged fluid velocity $\bar{u}(r)$ were calculated using Reichardt's [30-31] empirical relationships, which are straightforward and accurate.

Equation (8) with the boundary conditions (11)-(13) was solved using the finite difference method [29]. The Nusselt number was determined based on the temperature distribution determined numerically using the following formula

$$
\mathrm{Nu}=\frac{2 h r_{w}}{k}=\frac{2 q_{w} r_{w}}{k\left(\left.T\right|_{r=r_{w}}-T_{m}\right)}
$$

The Nusselt number was evaluated for various Reynolds and Prandtl numbers, and the results are listed in Table 1 [29].

Table 1. Nusselt Nu number as a function of the Reynolds and Prandtl numbers obtained from the solution of the energy conservation equation for fully developed turbulent flow in

\begin{tabular}{|c|c|c|c|}
\hline $\operatorname{Pr}$ & $10^{5}$ & $3 \cdot 10^{5}$ & $10^{6}$ \\
\hline 0.1 & 48.62 & 104.68 & 256.61 \\
\hline 0.2 & 76.78 & 172.57 & 437.11 \\
\hline 0.5 & 138.97 & 327.20 & 860.91 \\
\hline 0.71 & 172.84 & 413.35 & $1,102,29$ \\
\hline 1 & 212.50 & 515.41 & $1,391.88$ \\
\hline 3 & 391.85 & 987.68 & $2,764.63$ \\
\hline 5 & 506.89 & $1,295.71$ & $3,677.45$ \\
\hline 7.5 & 614.66 & $1,586.18$ & $4,544.73$ \\
\hline 10 & 700.78 & $1,818.99$ & $5,242.89$ \\
\hline 12.5 & 773.51 & $2,015.88$ & $5,834.61$ \\
\hline 15 & 836.98 & $2,187.81$ & $6,352.24$ \\
\hline 30 & $1,115.04$ & $2,941.80$ & $8,624.88$ \\
\hline 50 & $1,362.53$ & $3,612.61$ & $10,647.89$ \\
\hline 100 & $1,768.51$ & $4,711.28$ & $13,959.35$ \\
\hline 200 & $2,273.65$ & $6,076.39$ & $18,067.10$ \\
\hline 1000 & $3,986.35$ & $10,692.06$ & $31,968.41$ \\
\hline
\end{tabular}
tubes with constant wall heat flux [29].

\begin{tabular}{|c|c|c|c|c|}
\hline Re & $3 \cdot 10^{3}$ & $5 \cdot 10^{3}$ & $7.5 \cdot 10^{3}$ & $10^{4}$ \\
\hline 0.1 & 7.86 & 9.42 & 11.13 & 12.69 \\
\hline 0.2 & 9.41 & 11.86 & 14.58 & 17.08 \\
\hline 0.5 & 12.65 & 16.96 & 21.81 & 26.31 \\
\hline 0.71 & 14.32 & 19.60 & 25.57 & 31.12 \\
\hline 1 & 16.22 & 22.61 & 29.86 & 36.61 \\
\hline 3 & 24.43 & 35.57 & 48.39 & 60.47 \\
\hline 5 & 29.56 & 43.64 & 59.94 & 75.36 \\
\hline 7.5 & 34.34 & 51.15 & 70.68 & 89.21 \\
\hline 10 & 38.16 & 57.14 & 79.24 & 100.25 \\
\hline 12.5 & 41.40 & 62.20 & 86.47 & 109.56 \\
\hline 15 & 44.23 & 66.62 & 92.78 & 117.70 \\
\hline 30 & 56.73 & 86.09 & 120.53 & 153.40 \\
\hline 50 & 67.98 & 103.56 & 145.36 & 185.32 \\
\hline 100 & 86.64 & 132.44 & 186.35 & 237.96 \\
\hline 200 & 110.11 & 168.69 & 237.71 & 303.83 \\
\hline 1000 & 190.70 & 292.75 & 413.17 & 528.61 \\
\hline
\end{tabular}

\begin{tabular}{|c|c|c|c|}
\hline Re & & & \\
\hline 0.1 & $3 \cdot 10^{4}$ & $5 \cdot 10^{4}$ & $7.5 \cdot 10^{4}$ \\
\hline 0.2 & & & \\
\hline 0.5 & 33.53 & 47.23 & 62.59 \\
\hline 0.71 & 68.75 & 82.31 & 111.63 \\
\hline 1 & 82.91 & 101.16 & 138.18 \\
\hline 3 & 145.31 & 220.65 & 169.15 \\
\hline 5 & 184.68 & 282.64 & 308.45 \\
\hline 7.5 & 221.38 & 340.53 & 480.68 \\
\hline 10 & 250.64 & 386.73 & 547.14 \\
\hline 12.5 & 275.31 & 425.71 & 603.25 \\
\hline 15 & 296.85 & 459.72 & 652.22 \\
\hline 30 & 391.25 & 608.73 & 866.75 \\
\hline 50 & 475.39 & 741.46 & $1,057.70$ \\
\hline 100 & 613.70 & 959.44 & $1,371.11$ \\
\hline 200 & 786.27 & $1,231.01$ & $1,761.37$ \\
\hline 1000 & $1,373.01$ & $2,153.24$ & $3,085.03$ \\
\hline & & & \\
\hline
\end{tabular}

The Nusselt numbers shown in Table 1 with Prandtl numbers ranging from 0.1 to 1,000 and Reynolds numbers ranging from 3,000 to $10^{6}$ were approximated by a product of two power functions of the Reynolds and Prandtl numbers

$$
\mathrm{Nu}=c_{1} \operatorname{Re}^{c_{2}} \operatorname{Pr}^{c_{3}}
$$

Unknown constants $c_{1}, c_{2}$, and $c_{3}$ occurring in the approximating function (16) were determined using the least squares method

$$
S\left(c_{1}, c_{2}, c_{3}\right)=\sum_{i=1}^{n_{\mathrm{Re}}} \sum_{j=1}^{n_{\mathrm{Pr}}}\left(\mathrm{Nu}_{i j}^{m}-\mathrm{Nu}_{i j}^{c}\right)^{2}=\min
$$


where:

$$
\mathrm{Nu}_{i j}^{m}=\mathrm{Nu}^{m}\left(\operatorname{Re}_{i}, \operatorname{Pr}_{j}\right)
$$

and

$\mathrm{Nu}_{i j}^{c}=\mathrm{Nu}\left(\operatorname{Re}_{i}, \operatorname{Pr}_{j}\right), i=1, \ldots, n_{\mathrm{Re}}, j=1, \ldots, n_{\mathrm{Pr}^{-}}$

given and approximated values of the Nusselt number, respectively, $n_{\mathrm{Re}}$ and $n_{\mathrm{Pr}}$ - the number of the Reynolds and Prandtl numbers which are considered in the sum (17). As $\mathrm{Nu}_{i j}^{m}$ the Nusselt numbers shown in Table 1 were taken. The values of $\mathrm{Nu}_{i j}^{c}$ were evaluated using Eq. (17).

Substituting the constants $c_{1}, c_{2}$, and $c_{3}$ determined from the condition (17) into the correlation (16), the following power-type formulas for turbulent flow in round tubes were obtained

$$
\begin{aligned}
& \mathrm{Nu}=0.02155 \operatorname{Re}^{0.8018} \operatorname{Pr}^{0.7095} \\
& 3 \cdot 10^{3} \leq \operatorname{Re} \leq 10^{6}, 0.1 \leq \operatorname{Pr} \leq 1 \\
& \mathrm{Nu}=0.01253 \operatorname{Re}^{0.8413} \operatorname{Pr}^{0.6179} \\
& 3 \cdot 10^{3} \leq \operatorname{Re} \leq 10^{6}, \quad 1<\operatorname{Pr} \leq 3 \\
& \mathrm{Nu}=0.00881 \operatorname{Re}^{0.8991} \operatorname{Pr}^{0.3911} \\
& 3 \cdot 10^{3} \leq \operatorname{Re} \leq 10^{6}, 3<\operatorname{Pr} \leq 1000
\end{aligned}
$$

The analysis of equations (18)-(20) shows that power exponents at the Reynolds and Prandtl numbers strongly depend on the Prandtl number. If the Prandtl number is smaller than one, power exponents with Reynolds and Prandtl numbers are almost equal to each other, as in the case of liquid metals when $\operatorname{Pr}<0.1[1,17,23]$. The exponent with Reynolds number increases with the Prandtl number, while the exponent of Prandtl number behaves conversely. As the Prandtl number increases, the power with Prandtl number decreases.

Equation (16) can be generalized to a tube of finite length by introducing the same multiplier as in the Gnielinski formula (4)

$$
\mathrm{Nu}=c_{1} \operatorname{Re}^{c_{2}} \operatorname{Pr}^{c_{3}}\left[1+\left(\frac{d_{w}}{L}\right)^{2 / 3}\right]
$$

The heat transfer correlations (18) - (20) were compared with the experimental data available in the literature taking into account the correction factor $\left[1+\left(d_{w} / L\right)^{2 / 3}\right]$.

\section{Comparison of the proposed correlations with experimental data}

The proposed correlation (18) was compared with the experimental results of turbulent air flow in the pipes and the correlation (20) with experimental data for water, which are available in the literature. Comparison of the results of experimental studies of doctoral dissertations [32-35] for the air flowing inside the heating pipe is shown in Fig. 1. Abraham [36] was the first who presented the experimental data for smooth tubes with uniform wall heat flux reported in these theses and used by him to verify the CFD results. Equation (18) gives lower values of Nusselt number as compared to experimental results, whereas the correlation of Dittus-Boelter (1) overpredicts them.

The proposed relationship (18) was also compared in Fig. 2 with the experimental data of Eiamsa-ard and Promvonge [37] for turbulent air flow in a tube with constant wall heat flux.

Measurements were performed in an electrically heated tube. The outer and inner diameter of the copper tube were $47 \mathrm{~mm}$ and $50 \mathrm{~mm}$, respectively. The tube was heated uniformly over the length of $1,250 \mathrm{~mm}$. An unheated calming section preceded heated pipe section.

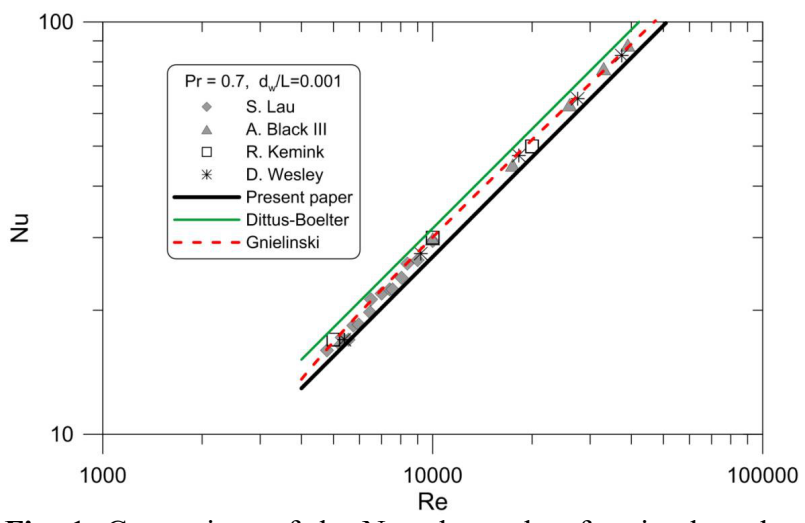

Fig. 1. Comparison of the Nusselt number for circular tubes obtained from the correlation (18) proposed in the paper with the experimental results of Lau, Black, Kemink, and Wesley [32-35] and the Gnielinski relationship (4) [19-20].

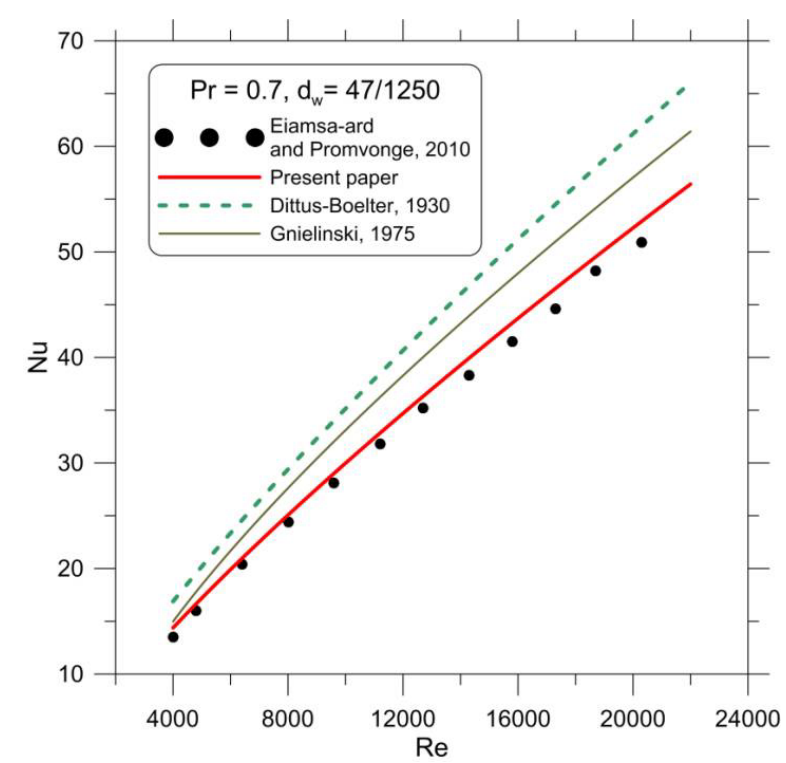

Fig. 2. Comparison of the correlation (18) proposed in the present paper and the correlation of Dittus-Boelter [10] and Gnielinski [19-20] with the experimental data of Eiamsa-ard| and Promvonge [37] obtained for turbulent air flow in a tube with constant wall heat flux. 
The hydrodynamically developed turbulent flow of water enters a uniformly heated tube. The Nusselt number determined experimentally was 10 to $20 \%$ higher than values predicted by the Dittus-Boelter equation. The discrepancy between the results of measurements and values of Nusselt number obtained from the Dittus-Boelter formula is greater for higher Reynolds numbers.

Then, Eq. (20) was compared with experimental results available of Allen and Eckert [16]. The smoothtube heat transfer results reported by Allen and Eckert [16] were obtained for developed turbulent flow of water under the uniform wall heat flux boundary condition at $\operatorname{Pr}=7$ and $\operatorname{Pr}=8$, and $1.3 \cdot 10^{4} \leq \operatorname{Re} \leq 1.11 \cdot 10^{5}$ [16]. Steel pipe with an inner diameter of $19.05 \mathrm{~mm}$ and a wall thickness of $1.5875 \mathrm{~mm}$ was heated electrically so that the heat flux at the internal surface of the tube was constant.

Allen and Eckert [16] found friction and heat transfer correlations for turbulent pipe flow of water at uniform wall heat flux for $\operatorname{Pr}=8$ experimentally. The friction factor and Nusselt number determined experimentally were approximated by the following functions [16]

$$
\begin{gathered}
\xi=0.00556+\frac{0.432}{\operatorname{Re}^{0.308}} \\
1.3 \cdot 10^{4} \leq \operatorname{Re} \leq 1.11 \cdot 10^{5}, \operatorname{Pr}=8 \\
\mathrm{Nu}=0.1576 \frac{\xi}{8} \operatorname{Re}^{1.0685} \operatorname{Pr}
\end{gathered}
$$

$$
1.3 \cdot 10^{4} \leq \operatorname{Re} \leq 1.11 \cdot 10^{5}, \operatorname{Pr}=8
$$

The relationship (20) proposed in this paper is close to the correlation (23) of Allen and Eckert [16](Fig.3). The best agreement is observed between Eq. (4) of Gnielinski [19-20]. The correlations of Dittus-Boelter (1) and $\mathrm{Li}$ and Xuan (7) give Nusselt number smaller than the correlation of Allen and Eckert (23). Evaluating the relative difference from the relation

$$
e=\frac{\mathrm{Nu}_{A-E}-\mathrm{Nu}}{\mathrm{Nu}_{\mathrm{A}-\mathrm{E}}} 100
$$

the correlations (20) and (1) were compared with (23) for the following Reynolds numbers: 10,000, 50,000, and 110,000 . The symbol $\mathrm{Nu}_{\mathrm{A}-\mathrm{E}}$ designates the Nusselt number obtained from the Allen and Eckert relation (23) while $\mathrm{Nu}$ is the Nusselt number calculated using Eq. (20) or (1). The relative differences for the Eq. (20) developed in the paper are: $14.2 \%, 3.9 \%$, and $0.08 \%$, respectively, whereas for the Dittus-Boelter equation (1) the differences $e$ are: $8.4 \%, 12.5 \%$, and $15.9 \%$.

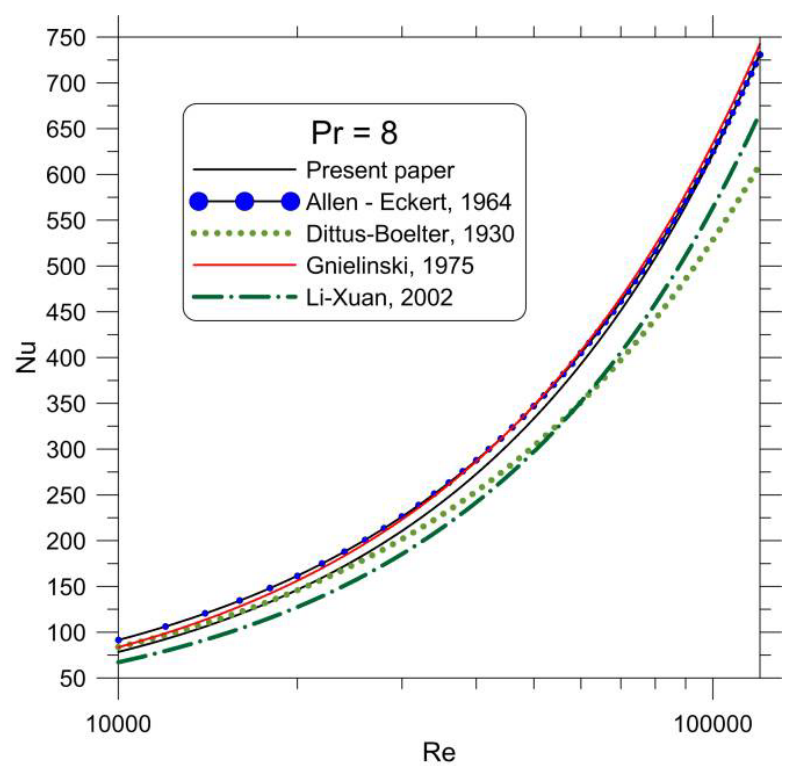

Fig. 3. Comparison of experimental correlation (23) of Allen and Eckert [16] with the correlation (20) proposed in the present paper, the correlation of Dittus-Boelter (1) [10], the Gnielinski relationship (4) [19-20], and the correlation (7) developed by Li and Xuan [25].

The correlation (20) found in the paper closely approximates the experimental equation (23) of Allen and Eckert for Reynolds numbers greater than 20,000 as compared to the Dittus-Boelter equation (1).

Comparisons of the correlations (8) and (20) to experimental data obtained by different researchers confirm quite well accuracy of the proposed relationships, especially when taking into account a variety of test conditions and different ways of experimental data processing.

\section{Conclusions}

The paper presents three power-type correlations of a simple form, which are valid for Reynolds numbers range from $3 \cdot 10^{3} \leq \operatorname{Re} \leq 10^{6}$, and for three different ranges of Prandtl number: $0.1 \leq \operatorname{Pr} \leq 1.0,1.0<\operatorname{Pr} \leq 3.0$, and $3.0<\operatorname{Pr} \leq 10^{3}$.

Formulas proposed in the paper have good theoretical basis, as they have been obtained by approximating Nusselt numbers obtained from the solution of the energy conservation equation for turbulent flow in a pipe by the method of least squares. Heat transfer correlations developed in the paper were compared with experimental results available in the literature. The performed comparisons confirm the good accuracy of the proposed correlations, better than the accuracy of the Dittus-Boelter correlation. Heat transfer correlations proposed in the paper can be used in a broader ranges of Reynolds and Prandtl numbers compared with a widely used correlation of Dittus-Boelter. They are also much simpler in comparison to the relationship of Gnielinski, which is also widely used in the heat transfer calculations. 


\section{References}

1. S. Kakaç, H. Liu, A. Pramuanjaroenkij, Heat exchangers. Selection, rating, and thermal design. $3^{\text {rd }}$ edition, CRC Press -Taylor \& Francis Group, Boca Raton (2012)

2. S. G. Penoncello, Thermal energy systems. CRC Press-Taylor and Francis Group, Boca Raton (2015).

3. D. Taler, Mathematical modeling and control of plate fin and tube heat. Energy Conversion and Management 96 (2015), 452-462.

4. M. Trojan, D. Taler, Thermal simulation of superheaters taking into account the processes occurring on the side of the steam and flue gas. Fuel 150 (2015), 75-87.

5. D. Taler, K. Kaczmarski, Mathematical modelling of the transient response of pipeline. Journal of Thermal Science 25 (2016), 1-9.

6. J. Taler, P. Dzierwa, D. Taler, M. Jaremkiewicz, M. Trojan, Monitoring of thermal stresses and heating optimization including industrial applications. Nova Publishers, (New York 2016).

7. P. Dzierwa, Optimum heating of pressure components of steam boilers with regard to thermal stresses, Journal of Thermal Stresses 39 (2016), 874-886.

8. P. Dzierwa, M. Trojan, D. Taler, K. Kamińska, J. Taler, Optimum heating of thick-walled pressure components assuming a quasi-steady state of temperature distribution, Journal of Thermal Science 25 (2016), 380-388.

9. J. Taler, P. Dzierwa, D. Taler, P. Harchut, Optimization of the boiler start-up taking into account thermal stresses, Energy 92 (2015), 160170.

10. F. W. Dittus, L. M. K. Boelter, Heat transfer in automobile radiators of the tubular type. The University of California Publications on Engineering 2 (1930) 443-461, Reprinted in Int. Commun. Heat Mass 12 (1985) 3-22.

11. R. H. S., Winterton, Where did the Dittus and Boelter equation come from?. Int. J. Heat Mass Tran. 41 (1998), 809-810.

12. W. H. McAdams, Heat Transmission, $3^{\text {rd }}$ edn., McGraw-Hill, (New York 1954).

13. A. P. Colburn, A method of correlating forced convectin heat transfer data and a comparison with fluid friction, Trans. AIChE 29(1933) 174-210.

14. E. N. Sieder, E. C. Tate, Heat transfer and pressure drop of liquids in tubes. Ind. Eng. Chem. 28(1936) 1429-1436.

15. R. L. Webb, A critical evaluation of analytical solutions and Reynolds analogy equations for turbulent heat and mass transfer in smooth tubes. Warme Stoffubertrag. 4 (1971), 197-204.

16. R. W. Allen, E. R. G. Eckert, Friction and heattransfer measurements to turbulent pipe flow of water $(\operatorname{Pr}=7$ and 8) at uniform wall heat flux. J. Heat Trans-T. ASME 86(1964), 301-310.
17. F. Kreith, R. M. Manglik, M. S. Bohn, Principles of heat transfer. $7^{\text {th }}$ edition, Cengage Learning, (Stamford 2011).

18. D. R. Mirth, S. Ramadhyani, D. C. Hittle, Thermal performance of chilled-water cooling coils operating at low water velocities. ASHRAE Transactions, Part 1, 99(1993), 43-53.

19. V. Gnielinski, Neue Gleichungen für den Wärmeund den Stoffübergang in turbulent durchströmten Rohren und Kanälen. Forsch. Ingenieurwes. (Engineering Research) 41 (1975),8-16.

20. V. Gnielinski, New equations for heat and mass transfer in the turbulent pipe and channel flow. Int. Chem. Eng. 16 (1976), 359-368.

21. G. K., Filonienko, Friction factor for turbulent pipe flow, Teploenergetika 1 (1954), no. 4, 40-44 (in Russian).

22. B. S. Petukhov, Heat transfer and friction in turbulent pipe flow with variable physical properties, in Advances in Heat Transfer, Vol. 6, (1970), 503-564, Edited by J. P. Hartnett and T. F. Irvine, Academic Press, (New York 1970).

23. S. Kakaç, Y. Yener, A. Pramuanjaroenkij, Convective heat transfer. $3^{\text {rd }}$ Edition, CRC Press Taylor \& Francis, Boca Raton (2014).

24. M. Li, T.S. Khan, E. Al-Hajri, Z. H. Ayub, Single phase heat transfer and pressure drop analysis of a dimpled enhanced tube. Appl. Therm. Eng. 101 (2016), 38-46.

25. Q. Li, Y. Xuan, Convective heat transfer and flow characteristics of $\mathrm{Cu}$-water nanofluid. Sci. China Ser. E: Technol. Sci. 45 (2002),408-416.

26. W. H. Azmi, K. Abdul Hamid, R. Mamat, K.V. Sharma, M. S. Mohamad, Effects of working temperature on thermo-physical properties and forced convection heat transfer of $\mathrm{TiO}_{2}$ nanofluids in water-Ethylene glycol mixture. Appl. Therm. Eng. 106 (2016), 1190-1199.

27. E. E. Wilson, A basis for rational design of heat transfer apparatus. Trans. ASME, 37 (1915), 47-82.

28. J. W. Rose, Heat-transfer coefficients, Wilson plots and accuracy of thermal measurements, Exp. Therm. Fluid Sci. 28 (2004), 77-86.

29. D. Taler, $A$ new heat transfer correlation for transition and turbulent fluid flow in tubes. Int. J. Therm. Sci.108 (2016), 108-122.

30. H. Reichardt, Vollständige Darstellung der turbulenten Geschwindigkeitsverteilung in glatten Leitungen, Z. Angew. Math. Mech. 31 (1951) no.7, 208-219.

31. H. Reichardt, The principles of turbulent heat transfer, Transl. by P.A. Scheck in Recent advances in heat and mass transfer, ed. by J. P. Hartnett, McGraw-Hill, (Boston 1961), 223-252.

32. S. Lau, Effect of plenum length and diameter on turbulent heat transfer in a downstream tube and on plenum-related pressure loss, Ph.D. Thesis, University of Minnesota, (1981). 
33. A. Black III, The effect of circumferentially-varying boundary conditions on turbulent heat transfer in a tube, Ph.D. Thesis, University of Minnesota, 1966.

34. R. Kemink, Heat transfer in a downstream tube of a fluid withdrawal branch, Ph.D. Thesis, University of Minnesota, (1977).

35. D. Wesley, Heat transfer in pipe downstream of a Tee, Ph.D. Thesis, University of Minnesota, (1976).

36. J. P. Abraham, E. M. Sparrow, W. J. Minkowycz, Internal-flow Nusselt numbers for the low-Reynoldsnumber end of the laminar-to-turbulent transition regime, Int. J. Heat Mass Tran. 54 (2011), 584-588.

37. S. Eiamsa-ard, P. Promvonge, Thermal characteristics in round tube fitted with serrated twisted tape, Appl. Therm. Eng. 30 (2010),16731682. 